\title{
EXTRAÇÃO E DOSAGEM DA ATIVIDADE DA POLIFENOLOXIDASE DO CAFÉ
}

\author{
Paulo Mazzafera*; Kátia Viviane Gonçalves; Milton Massao Shimizu \\ Depto. Fisiologia Vegetal - Unicamp/IB, C.P. 6109 - CEP: 13083-970 - Campinas, SP. \\ *Autor correspondente <pmazza@obelix.unicamp.br>
}

RESUMO: A atividade de polifenoloxidase (PFO) tem sido usada como indicadora da qualidade de bebida de café. Foram feitas comparações entre o método tradicionalmente usado para extração de polifenoloxidase de café e outro, onde impediu-se a oxidação de fenóis durante a extração, com posterior eliminação por filtração em coluna de exclusão. Um método intermediário entre os dois também foi testado. As medições de atividade foram feitas por espectrofotometria e por consumo de $\mathrm{O}_{2}$. Os métodos tradicionais de extração e dosagem da atividade de PFO sofrem forte interferência de fenóis presentes no extrato, não permitindo reprodução dos dados publicados na literatura. Por espectrofotometria foi possível diferenciação apenas entre café de bebida Mole de cafés de bebida Dura e Rio, mas não entre as duas últimas. Café de melhor qualidade, bebida Mole, apresentou maior atividade de PFO. Extração de PFO na presença de antioxidantes e complexadores de fenóis, seguida pela eliminação dos mesmos por cromatografia de exclusão é essencial para uma avaliação correta. Entretanto, usando este procedimento e consumo de $\mathrm{O}_{2}$, a atividade de PFO também não diferenciou os três cafés testados, exceto o Mole dos dois outros. No lugar de DOPA (3,4 dihidroxifenilalanina), usado comumente nas dosagens por espectrofotometria, sugere-se o emprego de ácido clorogênico (ácido 5-cafeoilquínico).

Palavras-chave: ácido clorogênico, café, qualidade de bebida

\section{EXTRACTION AND ACTIVITY DETERMINATION OF POLYPHENOLOXIDASE IN COFFEE}

\begin{abstract}
Polyphenoloxidase (PFO) activity has been used to indicate the quality of coffee beverage. A traditional extraction method used for coffee polyphenoloxidase was compared to another in which phenol oxidation was avoided and phenols were eliminated by exclusion chromatography. An intermediate method was also tested. Activities were obtained by spectrophotometry, which is commonly used for coffee PFO determination, and $\mathrm{O}_{2}$ consumption. The traditional extraction method and spectrophotometry are inacurate to measure PFO activity since there is a significant interference of phenols present in the extracts. Consequentely, the data reported in the literature are not reproducible. PFO activity differentiated Soft coffee from Hard and Rio, but not between the lost two. Soft coffee presented higher PFO activity. For an accurate activity determination, antioxidants and phenol complexation is essential during extraction, as well as their elimination by exclusion chromatography. However, using this procedure and $\mathrm{O}_{2}$ consumption, PFO activity could still not differentiate the three coffee qualities, except Soft from the other two. Instead of 3,4dihydroxyphenylalanine, it is suggested that chlorogenic acid (5-caffeoylquinic acid) should be used as substrate. Key words: chlorogenic acid, coffee, quality of beverage
\end{abstract}

\section{INTRODUÇÃO}

A procura por um parâmetro químico e de boa precisão para determinar a qualidade da bebida do café tem sido intensa, mas até então sem resultados comprovadamente positivos. Ainda existe a necessidade de provadores especializados, que dependendo do treinamento, ou mesmo da frequência que provam determinados tipos de café ou também da região em que atuam, podem desenvolver habilidades sensoriais distintas. Isto acarreta distorções, fazendo com que frequentemente haja discordância entre amostras provadas por diferentes provadores.

São muitos os trabalhos sobre os componentes do café e a sua influência na qualidade da bebida (Clifford, 1985). Entretanto, ao ser torrado, o café tem a grande maioria destes compostos alterados e outros novos formados, gerando uma situação mais complexa ainda. Mesmo técnicas mais modernas, tal como espectroscopia no vermelho próximo (NIRS), têm falhado na distinção entre cafés de melhor ou pior qualidade (Downey \& Spengler, 1996; Downey et al., 1994, 1997). Uma descoberta feita por Amorim \& Silva (1968) tem sido amplamente utilizada como indicadora da qualidade da bebida. Estes autores observaram que café de boa bebida (bebida Mole) apresentava maior atividade de polifenoloxidase (PFO) que café de bebida ruim (bebida Rio). Amorim e colaboradores (Amorim \& Josephson, 1975; Amorim \& Amorim, 1977; Amorim et al., 1974, 1975; Melo \& Amorim, 1975; Oliveira et al., 1977) estenderam este trabalho, sugerindo que em cafés de bebida inferior havia o comprometimento da estrutura celular, pela alteração nas membranas, de forma que a enzima, exclusiva de plastídeos, entrasse em contato 
com compostos fenólicos, armazenados preferencialmente no vacúolo. No processo, haveria a oxidação de fenóis, que convertidos a quinonas reagiriam com proteínas, inclusive a PFO, explicando sua menor atividade em café de menor qualidade. Assim, como bem colocado por Clifford (1985), não existe relação direta da PFO com a qualidade de bebida, mas, a sua atividade estaria relacionada com o processo de perda de qualidade. Em nenhum momento Amorim \& Silva (1968) sugeriram que PFO pudesse ser utilizada como um discriminador da qualidade de bebida, mas sim, como informação adicional. Oliveira et al. (1977) verificaram diferenças na atividade desta enzima somente entre cafés de bebida Rio e Mole.

Recentemente, porém, várias comunicações em congressos especializados em café (Chagas et al., 1996a, b, c; Pereira et al., 1996; Souza et al., 1996) usaram a atividade de PFO como diferenciadora da qualidade da bebida, baseados no trabalho de Carvalho et al. (1994). Nesse trabalho, em 380 amostras de café, classificadas entre estritamente Mole, apenas Mole, Mole, Dura, Riada e Rio, foi analisada a atividade daPFO utilizando-se uma adaptação do protocolo de extração de Draetta \& Lima (1976) e o de Ponting \& Joslyn (1948). Em 1997, outros autores publicaram trabalho semelhante, mas com número bem menor de amostras (Corrêa et al., 1997). Nos dois trabalhos, os autores sugerem que é possível distinguir a qualidade da bebida com base na atividade de PFO, estabelecendo inclusive, uma tabela delimitando faixas de valores para cada tipo de café. Uma diferença entre os trabalhos de Carvalho et al. (1994) e Corrêa et al. (1997), é que os primeiros apresentaram os dados de atividade de PFO em unidades de absorbância / min.g de amostra, não especificando com base em quanto tempo de reação isto foi determinado. Corrêa et al. (1997) apresentaram os dados em forma de gráfico (absorbância $X$ tempo - medidas de absorbância foram tomadas a cada 5 minutos).

Mazzafera \& Robinson (2000) utilizaram o consumo de $\mathrm{O}_{2}$ para determinar a atividade de PFO em café, observando que os dados obtidos na caracterização da enzima não correspondiam com aqueles obtidos por Draetta \& Lima (1976). Consumo de $\mathrm{O}_{2}$ é considerado o método mais adequado para a determinação de PFO (Mayer \& Harel, 1991; Steffens et al., 1994; Lea, 1995; Whitaker, 1995; Martinez \& Whitaker, 1995). Uma das diferenças observadas foi o ácido clorogênico, que havia sido determinado por Draetta \& Lima (1976) como um substrato ruim para PFO de café, mas foi caracterizado por Mazzafera \& Robinson (2000) como o melhor entre vários testados. As diferenças entre esses trabalhos podem provavelmente ser explicadas pelos métodos de extração e de determinação da atividade utilizados. Apenas no trabalho de Mazzafera \& Robinson (2000) protegeu-se o extrato da oxidação de fenóis, eliminou-se fenóis por filtração em cluna e a determinação de atividade foi feita pelo consumo de $\mathrm{O}_{2}$. Nos outros trabalhos sobre PFO em café utilizou-se espectrofotometria para determinar a atividade de PFO, com leitutras de absorbância em $420 \mathrm{~nm}$. A razão deste valor é que, no geral, compostos fenólicos oxidados absorvem luz neste comprimento de onda. A oxidação de fenóis se dá em função da captura de elétrons por dois átomos de cobre que se encontram no sítio ativo da enzima, havendo consumo de $\mathrm{O}_{2}$ durante o processo. Porém, para aqueles que trabalham com bioquímica de café, é conhecido que se não houver proteção por antioxidantes, inibidores de PFO ou complexadores de fenóis, extratos protéicos tornam-se rapidamente oxidados (marrons) durante a preparação, ou seja, PFO causa a oxidação de fenóis presentes no próprio tecido de café, sejam sementes, folhas, raízes, etc. Assim, seria de se esperar que não havendo proteção contra a oxidação dos fenóis endógenos e/ou sua eliminação do extrato, as leituras em $420 \mathrm{~nm}$ certamente não serão precisas.

No presente trabalho foram avaliados três métodos de extração de PFO utilizando-se três tipos de cafés diferindo na qualidade bebida, sendo feitas as posteriores dosagens de atividades por espectrofotometria e consumo de $\mathrm{O}_{2}$.

\section{MATERIAL E MÉTODOS}

\section{Material vegetal e extração}

Amostras de café bebida Rio, Dura e Mole foram cedidas pela Cooperativa dos Cafeicultores de Guaxupé (Guaxupé, MG). O material foi moído em moinho de facas com peneira de 30 mesh e armazenado em freezer. Para evitar qualquer tipo de aquecimento no material, foram colocadas quantidades pequenas e coletou-se 0 material que passou imediatamente pela peneira. Cada amostra foi submetida ao processo repetidas vezes até obter-se a quantidade necessária.

Foram adotados três procedimentos para a extração de proteínas, como mostrado abaixo. Proteínas nos extratos foram determinadas com o reagente de Bradford (1976).

Método 1 - Conforme descrito por Carvalho et al. (1994) e Corrêa et al. (1997). A $1 \mathrm{~g}$ de material adicionou-se $10 \mathrm{~mL}$ de tampão fosfato de sódio $0,1 \mathrm{~mol}$ $\mathrm{L}^{-1}, \mathrm{pH} 6,0$, a $4^{\circ} \mathrm{C}$, e o material foi deixado em banho de gelo sob agitação por $10 \mathrm{~min}$. Em seguida o extrato foi filtrado em papel de filtro comum, e o filtrado mantido em gelo para posterior dosagem de atividade.

Método 2 - O mesmo que o anterior, com as seguinte modificação: os extratos obtidos foram adicionalmente filtrados em colunas de exclusão Sephadex G25 (minicolunas PD-10, Amershan Pharmacia), que separa proteínas de fenóis e de outras moléculas de massa menor que $5 \mathrm{kDa}$. A eluição das proteínas da coluna foi feita com tampão fosfato $0,1 \mathrm{~mol}$ $\mathrm{L}^{-1}, \mathrm{pH} 6,0$, e o extrato mantido em gelo. 
Método 3 - Conforme deescrito por Mazzafera \& Robinson (2000). $1 \mathrm{~g}$ de material foi extraído com 10 $\mathrm{mL}$ de tampão fosfato de sódio $0,1 \mathrm{~mol} \mathrm{~L}^{-1}, \mathrm{pH} 7,0$, a $4^{\circ} \mathrm{C}$, contendo $1 \%$ de ácido ascórbico. Também adicionou 100 $\mathrm{mg}$ de polivinilpolipirrolidona (PVPP) no extrato. Após agitação por 10 min em banho de gelo, o extrato foi centrifugado $\left(4^{\circ} \mathrm{C}\right)$ a $36.000 \mathrm{~g}$ por $15 \mathrm{~min}$, e o sobrenadante foi filtrado em minicolunas PD-10. A eluição das proteínas da coluna foi feita com tampão fosfato $0,025 \mathrm{~mol} \mathrm{~L}^{-1}, \mathrm{pH} 6,0$, e o extrato mantido em gelo.

\section{Atividade de PFO}

Foram utilizados dois substratos para as dosagens, DOPA (3,4 - dihidroxifenilalanina) e ácido clorogênico (CGA - ácido 5-cafeoilquínico). DOPA tem sido usado como substrato na maioria dos trabalhos sobre PFO e qualidade de bebida. Nos ensaios sua concentração final foi $4 \mathrm{mM}$, como usado por Carvalho et al. (1994) e Corrêa et al. (1997) - 8 mg de DOPA dissolvidos em $10 \mathrm{~mL}$ de tampão fosfato $0,1 \mathrm{~mol} \mathrm{~L}^{-1}, \mathrm{pH}$ 6,0 . CGA estava presente na reação na concentração final de $1 \mathrm{mM}$ (Mazzafera \& Robinson, 2000). A atividade de PFO foi feita espectrofotometricamente e por consumo de $\mathrm{O}_{2}$.

Dosagem espectrofotométrica: A $950 \mu \mathrm{L}$ de tampão fosfato $0,1 \mu \mathrm{ol} \mathrm{\textrm {L } ^ { - 1 }}, \mathrm{pH} 6,0$, contendo DOPA ou CGA, adicionou-se $50 \mathrm{~mL}$ de extrato do método 1 , ou $70 \mu \mathrm{L}$ de extratos dos métodos 2 ou 3 . O maior volume dos dois últimos se deve ao fato de que na filtração em PD-10 existe uma diluição de $40 \%$ do extrato. Imediatamente após a adição do extrato na cubeta de leitura, foi feita a leitura de absorbância em $420 \mathrm{~nm}$, e a partir daí a cada 5 minutos, até 20 minutos. A primeira leitura foi considerada como a leitura do tempo zero e o valor medido foi descontado dos valores obtidos nos tempos posteriores.

A dosagem pelo oxímetro utilizou o equipamento Respire 1 (Hansatech, UK). A $850 \mu \mathrm{L}$ de tampão fosfato $0,025 \mathrm{~mol} \mathrm{~L}^{-1}, \mathrm{pH} \mathrm{6,0}$, adicionou-se 100 (extrato do método 1) ou $140 \mu \mathrm{L}$ (extratos to método 2 e 3 ) de extrato e, em seguida, $50 \mu \mathrm{L}$ de CGA $20 \mathrm{mM}$ (concentração final de $1 \mathrm{mM}$ ). A medida de consumo de $\mathrm{O}_{2}$ foi conduzida por 150 segundos, sendo utilizados para os cálculos de atividade os primeiros 90 segundos de reação.

\section{Análises de fenóis}

O conteúdo de fenóis nos extratos protéicos foi determinado utilizando ácido fênico como padrão e de acordo com o método de Swain \& Hillis (1959). Também, alíquotas de $5 \mu \mathrm{L}$ dos extratos foram aplicadas em placas cromatográficas de camada delgada de celulose (Merck) e desenvolvidas com n-butanol:ácido acético:água - 6/ 1/2, v/v/v (Mazzafera \& Magalhães, 1989). Em adição aos extratos protéicos, foram feitos extratos alcoólicos dos cafés $(1 \mathrm{~g}$ de café moído foi agitada por $2 \mathrm{~h}$ na temperatura ambiente com $10 \mathrm{~mL}$ de etanol $80 \%$, com posterior filtração), que também foram aplicados nas placas. A observação da separação dos fenóis foi feita em câmara de UV $254 \mathrm{~nm}$, com e sem vapores de amônia. Alíquotas dos extratos protéicos e dos etanólicos também foram analisadas por cromatografia líquida de alta eficiência (HPLC), com detecção em UV a 280 nm (Mazzafera et al., 1998). Nos extratos etanólicos, CGA foi determinado também em HPLC, com detecção em 313 nm (Mazzafera, 1997).

Para todas as determinações e dosagens realizadas, foram feitas quatro repetições.

\section{RESULTADOS E DISCUSSÃO}

Os extratos protéicos preparados pelo método 1 mudaram de cor muito rapidamente, e logo após a filtragem apresentavam-se bastante escurecidos, devido à oxidação de fenóis. Entretanto, após a filtração em PD10 , no método 2, a coloração ficou apenas levemente marrom. No método 3, o extrato ficou praticamente incolor, o que é desejável em extratos protéicos de plantas utilizados em dosagens enzimáticas. A Figura $1 \mathrm{~A}$ mostra estas diferenças com extratos feitos a partir do café de bebida Mole. É evidente a vantagem em se adicionar ácido ascórbico, cuja função é manter os fenóis na foma reduzida. Nesta situação dois pontos devem ser considerados; o primeiro é que mesmo na presença deste antioxidante existe consumo de $\mathrm{O}_{2}$, pois ele reduz imediatamente os fenóis oxidados pela PFO, não os deixando formar quinonas. Segundo, que havendo o esgotamento de ácido ascórbico, que se oxidará completamente ao final de um certo tempo, haverá o desenvolvimento de coloração marrom por ação da PFO. Assim, a adição de ácido ascórbico e filtração em Sephadex G-25 (PD-10) são complementares, pois a primeira reduz a oxidação e a segunda elimina os fenóis do extrato protéico. Uma situação intermediária, ou seja adição de ácido ascórbico mas sem passagem por coluna de exclusão, não é interessante para medidas de atividade por consumo de $\mathrm{O}_{2}$, pois ainda que mantidos na forma reduzida, haveria interferência de fenóis endógenos, pois eles estariam sendo oxidados antes de serem reduzidos pelo antioxidante.

A dosagem de fenóis nos extratos protéicos obtidos pelo método 1 apontaram que nos $50 \mu \mathrm{L}$ de extrato usados na dosagem espectrofotométrica havia $65,1,78,8$ e 57,6 mg nas amostras de café Rio, Duro e Mole, respectivamente. Traços de fenóis foram detetados nos extratos do método 2 e nada foi detetado nos extratos do método 3 , ambos filtrados em PD-10. A coloração levemente marrom do extrato 2 deve-se, muito provavelmente, a um certo grau de complexação de quinonas com proteínas.

A cromatografia em placa de celulose de amostras de extratos obtidos pelo método 1 foi bastante semelhante entre os três tipos de cafés. A Figura 1B mostra o extrato protéico e etanólico de bebida Mole, 
sendo evidentes as diferenças qualitativas entre eles. No extrato protéico nota-se a presença de intensa fluorescência na base do cromatograma, a partir do ponto de aplicação da amostra, indicando compostos mais polares, provavelmente quinonas. A mancha mais intensa no meio da cromatografia, indicada pela seta, corresponde a CGA, e na amostra do extrato protéico existe menor intensidade da mesma.

As análises em HPLC não mostraram diferenças quantitativas (Tabela 1) e no perfil de eluição (Figura 2) de fenóis nos extratos de cafés obtidos pelo método 1 . Dois compostos foram identificados como CGA e cafeína. Em comparação com extratos etanólicos, apenas o pico 2 não foi detectado. Café Arabica normalmente possui de 4 a 5\% de CGA (Clifford, 1985), o que está de acordo com os dados da Tabela 1. Os maiores valores nos extratos etanólicos que nos protéicos pode ser devido ao fato de CGA ser mais solúvel em etanol, o tempo de extração em etanol ter sido mais longo e, também, por ter sido oxidado por PFO no extrato protéico, que é aquoso.

As maiores atividades de PFO foram obtidas com extratos de café de bebida Mole, tendo CGA como substrato. Para este tipo de café e este substrato (Figura 3), após 5 minutos de reação ocorreu diminuição da velocidade de formação de produtos que absorvem em $420 \mathrm{~nm}$, ou seja, há tendência de estabilização das curvas, o que indica limitação de substrato. Exceto as dosagens com extratos obtidos pelo método 1, nos outros CGA foi melhor substrato que DOPA, quando feitas as comparações entre os tipos de café. Por exemplo, para os métodos 2 e 3 , extratos de café de bebida Mole apresentaram maior atividade com CGA do que quando dosados com DOPA. O mesmo se repete se comparados Dura/CGA com Dura/DOPA, e Rio/CGA com Rio/DOPA. Mazzafera \& Robinson (2000) observaram que CGA era melhor substrato que DOPA para a dosagem de PFO de sementes, folhas e raízes de café.

A Figura 4 traz os dados também no caso das dosagens com o oxímetro, utilizando CGA como substrato não foi possível a diferenciação entre cafés de bebida Dura e Rio, como também ocorrido com o método espectrofotométrico (Figura 3). Fica evidente, que existe interferência de fenóis presentes nos extratos, uma vez que o consumo de $\mathrm{O}_{2}$ foi maior no extrato obtido pelo método 1. A dosagem com extrato de bebida Mole obtido com método 2 foi um pouco inferior aos extratos dos dois outros métodos. Considerado o tempo de cinco minutos de incubação nas medidas espectrofotométricas, o que é próximo ao tempo para as medidas de consumo de $\mathrm{O}_{2}$, isso se repetiu. Talvez isto reflita algum tipo inibição/ inativação de PFO por fenóis. Amorim e colaboradores (Amorim \& Josephson, 1975; Amorim et al., 1974, 1975) demonstraram que PFO pode se ligar a fenóis oxidados, afetando sua migração em gel de poliacrilamida. Esta é uma das hipóteses levantadas por esses autores para a diminuição da atividade de PFO em café.
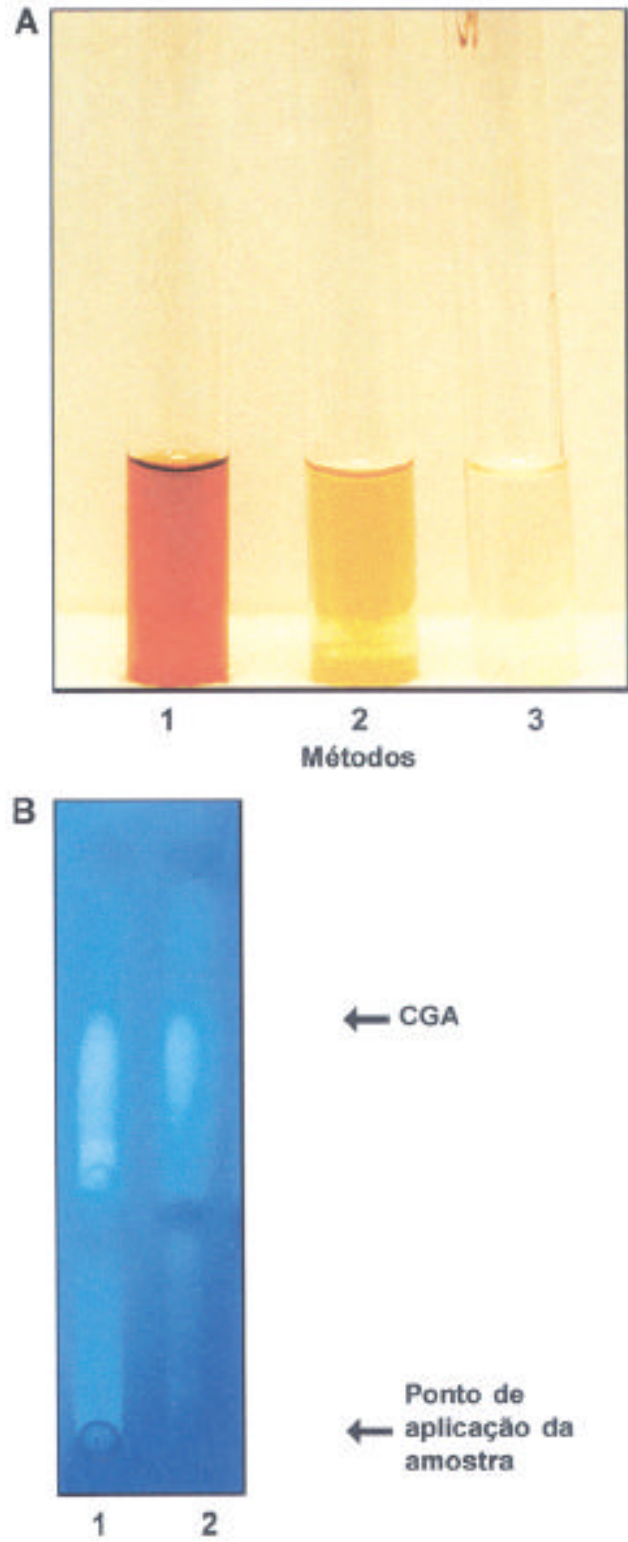

Figura 1 - Extratos protéicos de café de bebida Mole preparados pelos métodos 1, 2 e 3 de extração (A); e cromatografia em camada delgada de celulose, com observação em 254 nm, após exposição à vapor de amônia, de extrato protéico obtido pelo método 1 (1) e de extrato etanólico (2) de café de bebida Mole. Para as bebidas Rio e Dura, o padrão de bandeamento foi o mesmo.

Tabela 1 - Concentração de ácido clorogênico em extratos protéicos obtidos pelo método 1 de extração, em extratos etanólicos, e teor nas sementes, calculado em função do extrato etanólico.

\begin{tabular}{lccc}
\hline $\begin{array}{l}\text { Tipo de } \\
\text { Bebida }\end{array}$ & $\begin{array}{c}\text { Extrato } \\
\text { Protéico* }^{*}\end{array}$ & $\begin{array}{c}\text { Extrato } \\
\text { Etanólico }\end{array}$ & $\begin{array}{c}\text { Teor de CGA } \\
\text { na semente }\end{array}$ \\
\hline Rio & $0,54 \mathrm{a}$ & $1,07 \mathrm{a}$ & $5,09 \mathrm{a}$ \\
Dura & $0,64 \mathrm{a}$ & $1,09 \mathrm{a}$ & $5,02 \mathrm{a}$ \\
Mole & $0,55 \mathrm{a}$ & $0,95 \mathrm{a}$ & $4,98 \mathrm{a}$ \\
\hline
\end{tabular}

Letras iguais indicam que não houve diferença estatística pelo teste de Tukey $(P>0.05)$. Médias de quatro repetições. 

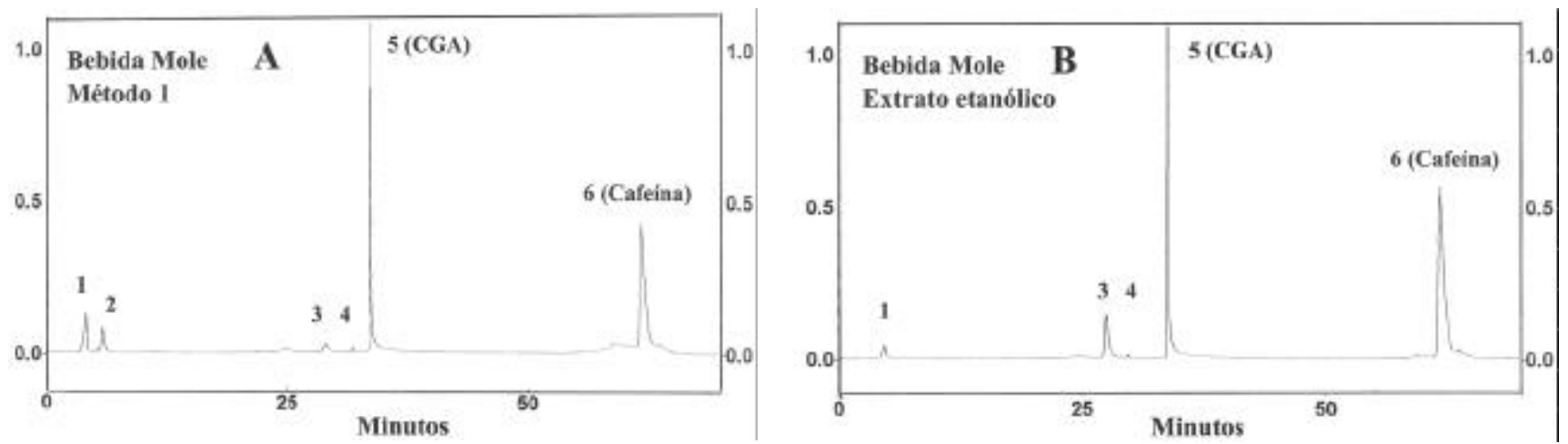

Figura 2 - Cromatografia líquida de alta eficiência de extrato protéico obtido pelo método 1 de extração (A) e extrato etanólico (B) de café bebida Mole. Detetor de UV operando em $280 \mathrm{~nm}$. Os picos 1, 2, 3 e 4 não foram identificados. Cafeína e CGA foram identificados por co-injeção das amostras com padrões puros.
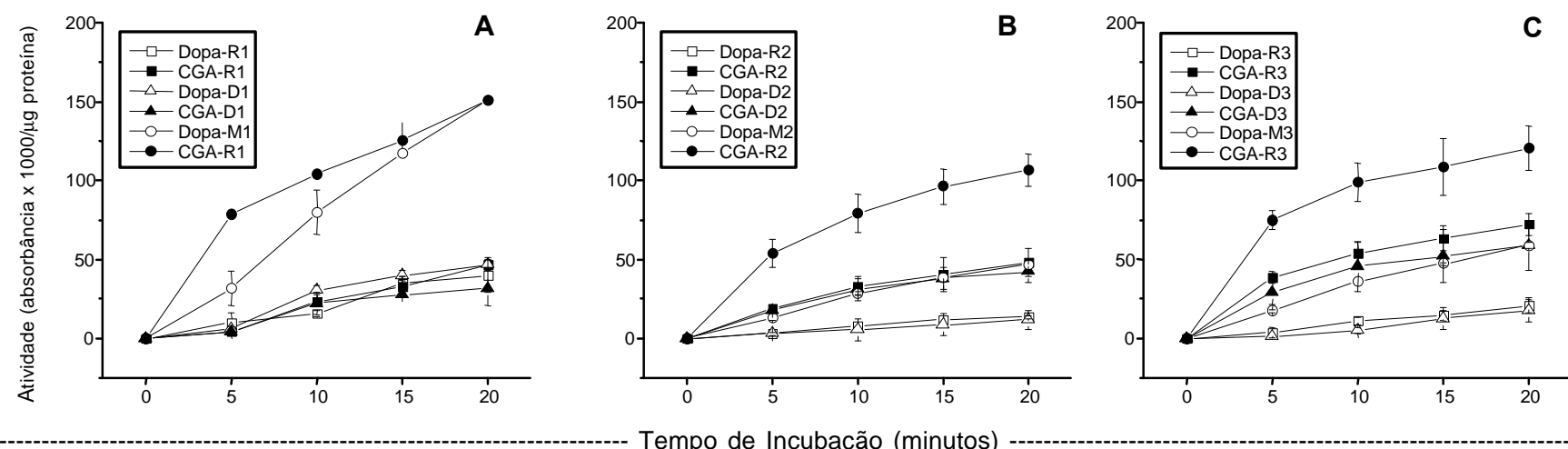

Figura 3 - Atividades de PFO em extratos protéicos obtidos pelos métodos 1 (A), 2 (B) e 3 (C) de extração. $R=C$ Café Rio, $D=$ Café Duro, M = Café Mole. Médias de quatro repetições. Barras indicam o desvio padrão.

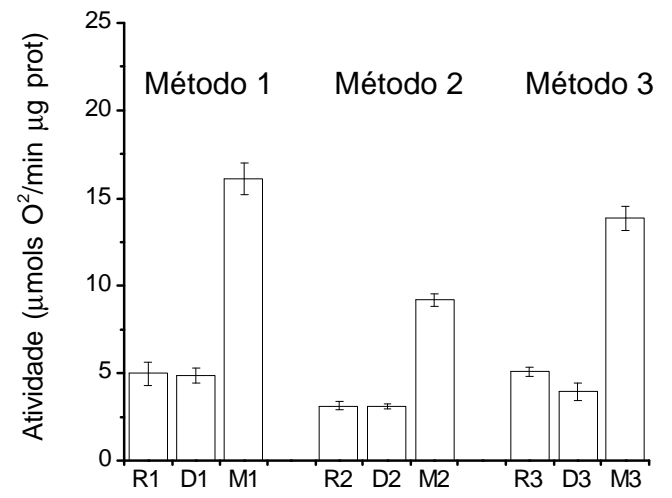

Figura 4 - Atividades de PFO em extratos protéicos de cafés de bebida Rio (R), Dura (D) e Mole (M), obtidos pelos métodos 1,2 e 3. CGA foi usado como substrato. Médias de quatro repetições. Barras indicam o desvio padrão.

\section{CONCLUSÕES}

Existem problemas nos métodos de extração e dosagem da atividade de PFO. Sugere-se que o uso da atividade de PFO como indicador de qualidade de bebida de café seja reavaliado. Durante a extração, deve-se impedir a oxidação de fenóis, assim como sua eliminação do extrato. A dosagem de atividade pelo consumo de $\mathrm{O}_{2}$ também é recomendada, por ser mais precisa que a espectrofotométrica.

\section{AGRADECIMENTOS}

Ao CNPq e à FAPESP, pelas bolsas de pesquisa (P. Mazzafera) e doutoramento (K.V. Gonçalves e M.M. Shimizu), respectivamente.

\section{REFERÊNCIAS BIBLIOGRÁFICAS}

AMORIM, H.V.; AMORIM, V.L. Coffee enzymes and coffee quality. In: ORY, R.L.; St ANGELO, A.J. (Ed.) Enzymes in food and beverages processing. Washington: ACS, 1977. p.27-56. (Symposium Series, 47)

AMORIM, H.V.; JOSEPHSON, R.V. Water-soluble protein- and non-protein components of Brazilian green coffee beans. Journal of Food Science, v.40, p.1179-1185, 1975 .

AMORIM, H.V.; SILVA, D.M. Relationship between the polyphenol oxidase activity of coffee beans and the quality of beverage. Nature, v.219, p.381-382, 1968

AMORIM, H.V.; TEIXEIRA, A.A.; MELO, M.; CRUZ, V.F.; MALAVOLTA, E. Chemistry of Brazilian green coffee and the quality of the beverage. III. Soluble proteins. Turrialba, v.24, p.304-308, 1974

AMORIM, H.V.; TEIXEIRA, A.A.; MELO, M.; CRUZ, V.F.; MALAVOLTA, E Chemistry of Brazilian green coffee and the quality of the beverage. 4. electrophoresis of soluble proteins in agar-gel and its interaction with chlorogenic acids. Turrialba, v.25, p.18-24, 1975.

BRADFORD, M.N. A rapide and sensitive method for the quantitation of microgram quantities of protein utilizing the principle of protein-dye binding. Analytical Biochemistry, v.72, p.248-254, 1976.

CARVALHO, V.D.; CHAGAS, S.J.R.; CHALFOUN, S.M.; BOTREL, N.; JUSTE JR., E.S.G. Relação entre a composição fisico-química e química do grão beneficiado e a qualidade de bebida do café. Pesquisa Agropecuária Brasileira, v.29, p.449-454, 1994.

CHAGAS, S.J.R.; CARVALHO, V.D.; COSTA, L.; SILVA, E.B. Caracterização química e qualitativa de cafés de alguns municípios da região da Zona da Mata. In: CONGRESSO BRASILEIRO DE PESQUISAS CAFEEIRAS, 22., Lindóia, 1996. Trabalhos apresentados. Lindóia, 1996a. p.47-48. 
CHAGAS, S.J.R.; CARVALHO, V.D.; COSTA, L.; SILVA, E.B. Caracterização química e qualitativa de cafés de alguns municípios da região do sul de Minas. In: CONGRESSO BRASILEIRO DE PESQUISAS CAFEEIRAS, 22., Lindóia, 1996. Trabalhos apresentados. Lindóia, 1996b. p. 46-47.

CHAGAS, S.J.R.; CARVALHO, V.D.; COSTA, L.; SILVA, E.B. Caracterização química e qualitativa de cafés de alguns municípios da região do Triângulo Mineiro/Alto Paranaíba. In: CONGRESSO BRASILEIRO DE PESQUISAS CAFEEIRAS, 22., Lindóia, 1996. Trabalhos apresentados. Lindóia, 1996c. p.48-50.

CLIFFORD, M.N. Chemical and physical aspects of green coffee and coffee products. In: CLIFFORD, M.N.; WILSON, K.C. (Ed.) Coffee: botany, biochemistry and production of beans and beverage. Westport: AVI Publishing Company, 1985. p.305-374.

CLIFFORD, M.N. Chlorogenic acids. In: CLARKE, R.J.; MACRAE, R. (Ed.) Coffee. London: Elsevier Applied Science Publishers, 1985. v.1, p.153-202.

CORRÊA, P.C.; SILVA, C.G.; MIANDA, L.C.G. Qualidade da bebida do café (Coffea arabica L.) avaliada por espectrofotometria. Revista Brasileira de Armazenamento, v.22, p.9-12, 1997.

DOWNEY, G.; BOUSSIONB, J.; BEAUCHÊNEB, D. Authentication of whole and ground coffee beans by near infrared reflectance spectroscopy. Journal of Near Infrared Spectroscopy, v.2, p.85-92, 1994.

DOWNEY, G.; BRIANDET, R.; WILSON, R.H.; KEMSLEY, E.K. Near- and mid-infrared spectroscopies in food authentication: Coffee varietal identification. Journal of Agricultural and Food Chemistry, v.45, p.4357-4361, 1997.

DOWNEY, G.; SPENGLER, B. Compositional analysis of coffee blends by near infrared spectroscopy. Irish Journal of Agriculture and Food Research, v.35, p.179-188, 1996

DRAETTA, I.S.; LIMA, D.C. Isolamento e caracterizaçao das polifenoloxidases do café. Coletâneas do Instituto de Tecnologia de Alimentos, v.7, p.13-28, 1976

LEA, A.G.H. Enzymes in the production of beverages and fruit juices. In: TUCKER, G.A.; WOODS, L.F.J. (Ed.) Enzymes in food processing. Glasgow: Blackie Academic \& Professional, 1995. p.221-249.

MARTINEZ, M.V.; WHITAKER, J.R. The biochemistry and control of enzymatic browning. Trends in Food Science and Technology, v.6, p.195-200, 1995.

MAYER, A.M.; HAREL, E. Phenoloxidases and their significance in fruit and vegetables. In: Fox, P.F. (Ed.) Food enzymology. London: Elsevier Applied Science, 1991. p.373-398.

MAZZAFERA, P. Maté drinking: caffeine and phenolic acid intake. Food Chemistry, v.60, p.67-71, 1997
MAZZAFERA, P.; GUERREIRO FILHO, O. Ultraviolet HPLC-derived profiles as a tool in Coffea taxonomy. Journal of Comparative Biology, v.3, p.15-20, 1998.

MAZZAFERA, P.; MAGALHÃES, A.C.N. Resistência induzida no complexo Coffea arabica L. - Hemileia vastatrix Berk. et Br: fenóis e enzimas. Turrialba, v.39, p.334-345, 1989.

MAZZAFERA, P.; ROBINSON, S.P. Characterization of polyphenol oxidase in coffee. Phytochemistry, v.55, p.285-296, 2000.

MELO, M.; AMORIM, H.V. Chemistry of brazilian green coffee and the quality of the beverage. VI. U.V. and visible spectral analysis and chlorogenic acids content on TCA soluble buffer extracts. Turrialba, v.25, p.243-248, 1975.

OLIVEIRA, J.C.; SILVA, D.M.; TEIXEIRA, A.A.; AMORIM, H.V. Atividade enzimática da polifenoloxidase, peroxidase e catalase em grãos de Coffea arabica L. e relações com a qualidade de bebida. Turrialba, v.27, p.75-82, 1977.

PEREIRA, R.G.F.A.; VILELA, E.R.; COELHO, K.F.; COSTA, L.; SILVA, E.B. Efeito dos níveis de adição de grãos defeituosos sobre a atividade da polifenoloxidase e lixiviação de potássio no café (Coffea arabica L.) In: CONGRESSO BRASILEIRO DE PESQUISAS CAFEEIRAS, 22., Lindóia, 1996. Trabalhos apresentados. Lindóia, 1996. p.45-46.

PONTING, J.D.; JOSLYN, M.A. Ascorbic acid oxidation and browning in apple tissue extracts. Archives in Biochemistry, v.19, p.47-63, 1948.

SOUZA, C.A.S.; SILVA, E.B.; MALTA, M.R.; CHAGAS, S.J.R.; COSTA, L. Avaliação da composição fisico-química e química de cafés provenientes de anos agrícolas e tipos de colheitas diferentes. In: CONGRESSO BRASILEIRO DE PESQUISAS CAFEEIRAS, 22., Lindóia, 1996. Trabalhos apresentados. Lindóia, 1996. p.51-52.

STEFFENS, J.C.; HAREL, E.; HUNT, M.D. Polyphenol oxidase. In: ELLIS, B.E.; KUROKI, G.W.; STAFFORD, H.A. (Ed.) Recent advances in phytochemistry. New York: Plenum Press, 1994. v.28, p.275-312.

SWAIN, T.; HILLIS, W.E. The phenolic constituents of Prunus domestica. I. The quantitative analysis of phenolic constituents. Journal of the Science of Food and Agriculture, v.10, p.63-68, 1959.

WHITAKER, J.R. Polyphenol oxidase. In: WONG, D.W.S. (Ed.) Food enzymes: Structure and mechanism. New York: Chapman \& Hall, 1995. p.271-307.

$\overline{\text { Recebido em } 01.08 .01}$ 